Running head: Mother traits and offspring sex

\title{
Mother traits and offspring sex in two threatened gazelle species in captivity
}

\author{
Eulalia Moreno ${ }^{(1)}$, María B. Ibáñez \& Andrés Barbosa ${ }^{(2)}$
}

Departamento de Ecología Funcional y Evolutiva, Estación Experimental de Zonas Áridas, Consejo Superior de Investigaciones Científicas (CSIC), Carretera de Sacramento s/n, 04120 La Cañada de San Urbano, Almería, Spain.

Tel.:+34950281045

Fax : +34950277100

E-mail: emoreno@eeza.csic.es

(1) Author for correspondence (EM): E-mail: emoreno@eeza.csic.es

(2) Present address: Museo Nacional de Ciencias Naturales, CSIC, José Gutiérrez Abascal, 2, E-28006 Madrid, Spain. 


\section{Abstract}

Since threatened species are generally incapable of surviving in their natural environments, ex situ conservation programs are required to preserve them from total extinction. Captive breeding provides the tool to rear sustained populations. Knowledge about biology of such species is critical for managing such breeding programmes. In this paper we look at the sex variation in calves surviving to 30 days in captive populations of two endangered polygynous gazelles, Gazella cuvieri and Gazella dama mhorr. We examined which of the following mother traits may affect sex allocation: her age, experience and inbreeding coefficient. Because twins are quite common in Cuvier's gazelle, we also analyze whether offspring sex is mediated by litter size in this gazelle. In both species the overall sex ratio did not differ from unity at the age of 30 days. These results support the suggestion that for a given population to be in equilibrium, a 1:1 calf sex ratio is to be expected, with females in good condition producing sons and females in poor condition producing daughters. We also found that offspring sex is not significantly related to the same mother traits in the two gazelles studied. Cuvier's gazelle findings showed that only maternal inbreeding influenced offspring sex, the less inbred the mother the higher the probability of producing sons. In contrast, none of the maternal traits studied were related to offspring sex in Mohor gazelle. Two non exclusive explanations are given to justify differences observed between these two species; one relate to a probable differential cost of producing either sex; the other refers to the actual homozygosis level in captive populations of each species. For Cuvier's gazelle litter size has no effect on offspring sex when the sex of the littermate is taken into account. This result fit predictions derived from Trivers-Willard model: mother in good conditions (less inbred) produce the sex with higher fitness returns (i.e., male), no matter if born at single or twins brood. Many variables are likely to affect progeny sex ratio. We have presently examined only a few. But our results might be of interest in management decisions and conservation programs such as reintroductions.

Key words: Cuvier's gazelle, ex-situ conservation, mohor gazelle, sex allocation, captive breeding. 


\section{Introduction}

Captive breeding of a threatened species is an important and in some cases very successful tool for species conservation. In the last few decades, recovery of some endangered species has relied on breeding programmes undertaken on their captive populations (Magin et al., 1994; Russello and Amato, 2004). Some biological problems confront this practice, however (e.g., low probability of long-term survival due to small population size, loss of genetic diversity,...). There are also organizational problems. Management of captive mammal populations is a complicated process requiring genetic and demographic analyses to guide the population toward a target size that will ensure its continued survival (Faust and Thompson, 2000). But in many cases this ideal target population size exceeds available space. To make the most efficient use of their restricted space, breeding centres must maintain an adequate sex ratio in each species depending on the characteristics of its breeding system.

In polygynous species, captive breeders tend to maintain a female-biased sex ratio of adults, the management of the non-breeding sexually mature males in the population representing one of the most important organizational problems to be faced (Faust and Thompson, 2000). Hence, identification of maternal variables affecting sex allocation of calves would be an useful tool for captive breeding of polygynous species, as reproductive herds could be formed by taking into account those traits in the mother that favour a specific sex.

Since the seventies the "Estación Experimental de Zonas Áridas" (EEZA-CSIC, Spain) has developed captive breeding programmes for two polygynous, endangered gazelle species: Gazella cuvieri (Ogilby, 1841) y G. dama mhorr (Bennett 1833). The Cuvier's gazelle is a medium-sized gazelle that can weigh up to $35 \mathrm{~kg}$, and could be found in a wide variety of habitats in hilly terrain, including the Moroccan highlands (from 60 to $2600 \mathrm{~m}$ asl; Loggers et al., 1992; Aulagnier and Thévenot, 1986). Females reach sexual maturity at 6 to 9 months, gestation is about 165 days, and twins represent up to $39 \%$ of births (Moreno and Espeso, 2008). It is in sharp decline in most of its range (Morocco, Tunisia, Algeria; Beudels et al., 2005) where its population seems to be highly fragmented. Their world population in captivity is about 219 individuals (Moreno and Espeso, 2008). G. dama mhorr is the largest species of the Gazella genus, with individuals weighing from 45 to $70 \mathrm{~kg}$. This species inhabited arid areas with sparse vegetation in North Africa (Barbosa and Espeso, 2005; Loggers et al., 1992; 
Kingdon, 1997; Aulagnier and Thévenot, 1986), although it is currently considered extinct in the wild (Walther, 1990; Beudels et al., 2005). Females reach sexual maturity at 9 to 12 months and have a gestation period of 197 days (Barbosa and Espeso, 2005; Walther, 1990). Their current world population in captivity is about 180 individuals (Espeso and Barbosa, 2010). The survival of these two species very much depends on their captive populations which are currently managed within respective European Endangered Species Programs (EEPs) at the Experimental Field Station "La Hoya" from the EEZA-CSIC.

In this paper, we pursue two aims. The first is to analyze variation in calf sex ratio in captive populations of two endangered polygynous gazelles, G. cuvieri and G. dama mhorr. Considering that perinatal mortality represents the most frequent cause of death in many species of mammals (Clutton-Brock et al., 1982; Blaxter and Hamilton, 1980), offspring costs would be expressed at that time, so we analyse sex variation in calves surviving to 30 days, when according to available data, perinatal mortality in captivity is the highest for both studied species (Alados and Escós, 1991; Barbosa and Espeso, 2005; Moreno and Espeso, 2008; see Kirkwood et al., 1987; Clutton-Brock et al., 1982 for other ungulate species).

We secondly explore which mother traits could affect offspring sex. Trivers and Willard (1973) proposed that when adaptive variance in reproductive success favours one sex (males in polygynous species), an adult female with above-average resources would be advantaged by producing more of that sex, whereas females with belowaverage resources would be advantaged by producing more of the reproductively stable sex (females in polygynous species). Following this assumption, in our study species, mothers in good condition would produce sons, while mothers in poor condition would produce daughters. It is well known that inbreeding can affect individual body condition and/or reproduction (Ralls et al., 1979; Cassinello, 1997, 2005; Gomendio et al., 2000), so that on average, individuals with higher inbreeding coefficients may have lower quality (Charlesworth and Charlesworth, 1987). We would then expect more inbred females to produce more daughters surviving to 30 days. Likewise, age has also been used as an estimation of maternal body condition, as well as a predominant determinant of progeny sex ratio among ungulates (Saltz, 2001; but see Hewison et al., 2002). Among large mammals, the female's capacity for motherhood might be strongly age dependent. Females usually start breeding before they reach adult body size and toward the end of their lifetime, their body condition decreases as a consequence of 
reproductive senescence. In this context, the male:female ratio might be expected to be low among first breeders, increase during the middle years of their lifetime, and decrease again in old animals (Williams, 1979; Clutton-Brock and Iason, 1986). Therefore, we would expect younger and older females to have more daughters. In polygynous ungulate managed within captive breeding programmes, females usually become members of a reproductive herd as soon as they are fertile. Then, we would expect primiparous females to produce more daughters than sons (Festa-Bianchet et al., 1995; Saltz, 2001; Côté and Festa-Bianchet, 2001), as they have to allocate resources to growth and reproduction at the same time (Festa Bianchet et al., 1995; LandeteCastillejos et al., 2004).

Twins are common in Cuvier's gazelle (Moreno and Espeso, 2008). It could be assumed that the cost of producing and rearing twins is higher than the cost of producing and rearing singles. We also analyze whether offspring sex is mediated by litter size as mother decision might be a trade-off between investing in the most costly sex (i.e., a male) vs investing in a larger brood.

\section{Methods}

The current captive population of Cuvier's gazelle at the EEZA-CSIC is descended from 4 wild-born individuals (1 male, 3 females; Moreno and Espeso 2008). The founder population of the Mohor has been controversial. Following the criteria of "unknown parents", Cano (1991) considered that 16 individuals (3 males and 13 females) were founders. Following the criteria of animals which had descendants, Barbosa and Espeso (2005) considered 11 founding individuals ( 2 males, 9 females). However, Ruiz López et al. (2009) using molecular information found that the founding population of G. dama mhorr was much smaller than previously assumed. The Mohor gazelle studbook pedigree have been recently reconstructed (Espeso \& Barbosa 2010) considering five founder individuals ( 1 male, 4 females) based on information taken from Cano (1991) and references therein; Valverde (2004); and information available in the historical files of the Experimental Field Station "La Hoya". We assume founders are unrelated to each other.

The data for 555 Cuvier's gazelle calves and 678 Mohor gazelle calves used in the analyses were taken from their studbooks (Espeso \& Barbosa, 2010; Moreno and Espeso, 2008). Maternal variables analyzed were inbreeding coefficient, age (in days), and experience (primiparous vs multiparous). Inbreeding coefficients were calculated 
using the SPARKS software programme (ISIS 2004). As mother age maintains nonlinear relationships with maternal investment we have calculated mother squared age as well to be included in the analyses. Throughout this paper offspring sex ratio refers to the proportion of males in the population surviving to 30 days.

Analyses were performed using SAS v. 9.1 statistical software (SAS Institute, Cary, NC, USA). A $\chi^{2}$ analysis (GENMOD SAS procedure) was used to analyze sex ratio variation in calves surviving to 30 days. To examine the effect of maternal age (raw and squared), maternal experience (primiparous vs multiparous females) and maternal inbreeding coefficient on the offspring sex ratio, generalized linear mixed models (SAS macro program GLIMMIX) were performed.

In all the analyses, offspring were used as statistical units. As some of them belong to the same mother in different breeding seasons, they are not totally independent. So, mother identity was introduced as a random factor to account for the non-independence of offspring from the same mother. As this study includes several decades of the breeding programmes (1975-2007 for G. cuvieri and 1971-2007 for G. dama mhorr), mother identity was nested within the year in the analyses in case different condition in different years influence offspring sex ratio.

For Cuvier's gazelle, where twins are common, litter size very likely affect offspring sex. Moreover, the sex of the littermates may not be independent as it may be more likely for a calf to be male if singleton or with a daughter than with a brother (see Cassinello and Gomendio, 1996; Carranza, 2004). As a way of including this likely influence in the analyses, we have built a factor that captures the investment of the mother when producing the focal offspring. It is a categorical factor (litter size $\mathrm{x}$ litter sex) with three levels: level 1, assigned to individual born with no other offspring (i. e., the focal offspring is a singleton); level 2, assigned to individuals born in twins and the non-focal offspring is a female; and level 3, assigned to individuals born in twins and the non-focal offspring is a male. This so built factor has been included as an independent variable in the analyses.

Model selection was carried out by removing, one by one, the effects that deviated most from statistical significance (Engqvist, 2005). 


\section{Results}

Table 1 shows range, mean and standard deviations for the continuous variables presently analysed for offspring of both G. cuvieri and G. d. mhorr.

The overall sex ratio (SR) of calves that survived to one month of life did not differ from unity in none of the species studied (G. cuvieri: $\mathrm{SR}=49 \%$ of male offspring, $\chi^{2}=0.031, \mathrm{p}=0.762, \mathrm{n}=555 ;$ G. d. mhorr: $\mathrm{SR}=51 \%$ of male offspring, $\chi^{2}=0.05, \mathrm{p}=$ $0.76, \mathrm{n}=678)$.

Results of the generalized linear mixed models are shown in Table 2. In G. cuvieri, offspring sex was significantly unaffected by mother identity, mother age, mother experience and litter size once the sex of the littermates is considered (litter size $\mathrm{x}$ littermate sex factor). Only the inbreeding of the mother was significantly related to offspring sex: the more inbreed the mother the higher the probability of producing daughters surviving to 30 days sex (Fig. 1). In G. d. mhorr offspring sex ratio at 30 days of age was unaffected by all the variables considered.

\section{Discussion}

In our gazelle species populations, the overall sex ratio did not differ from unity at the age of 30 days. This result can be the consequence of a 1:1 sex ratio at birth, but also the result of a sex differential perinatal mortality. Results by Alados and Escós (1994) and by Cano (1991) support the former explanation as they found the sex ratio did not differ from unity at birth for any of the studied species. According to the sex allocation theory (Trivers and Willard, 1973), in polygynous species, the better the maternal body condition the higher her probability of producing a male, as this sex represents a higher fitness return for the mother. However, a 1:1 sex ratio (Fisher 1930) is also compatible with Trivers and Willars (1973) hypothesis if applied at population level, with females in good condition producing sons and females in poor condition producing daughters (see Frank, 1990; Hewison et al., 2002).

Previous studies have found that, on average, higher levels of inbreeding lead to worse individual body condition (Gomendio et al., 2000; Cassinello et al., 2001; Cassinello, 2005; Roldan et al., 2006). In our populations, the inbreeding coefficient varies widely among individuals in both species studied (Table 1); we can then safely assume that the body condition of the individuals studied would vary accordingly. The lack of progeny sex-ratio bias found in these two gazelle species supports the claim for 
equilibrium within the population, with mothers in better or poorer condition producing either sons or daughters, respectively.

In relation to mother traits affecting offspring sex, results for the two species studied are not in accordance. As expected, results for G. cuvieri showed that females with a lower level of inbreeding had a higher probability of having sons surviving to 30 days than females more inbreed, which were more prone to produce daughters. In Mohor gazelle none studied variable affected offspring sex.

The relationship between offspring sex and maternal inbreeding level may represent an investment to maximise future return by progeny. In gazelles, as in other polygynous mammals, the variance in male reproductive success exceeds that of females (Clutton-Brock et al., 1982, 1986; Hewison et al., 1999; Wolff, 1988; Knut et al., 2007) and this success depends on calf weight and/or adult body size (Clutton-Brock and Iason, 1986, Landete-Castillejos et al., 2005) because they are related to their fighting ability (Knut et al., 2007; Kühl et al., 2007). Inbreeding has been shown to influence body size in domestic, captive and laboratory animals as well (Charpentier et al., 2006; Coltman et al., 1998; Fredrickson and Hedrick, 2002; Wright et al., 2008). Hence, a male born to a highly inbred mother would have a smaller body size than those born to less inbred mothers and consequently this male would leave fewer surviving descendants (according to Trivers and Willard, 1973).

Against expectation, for G. dama mhorr we found no significant relationships between inbreeding coefficient and the sex of offspring surviving to 30 days. Several non exclusive explanations can be given for justifying observed differences between the two gazelles studied. It could be suggested a differential cost of producing either sex in each species. Maternal investment can be assessed by examining two phases of the reproductive cycle, gestation and lactation. The cost of gestation can be measured by offspring birth weight (Byers and Moodie, 1990; Ono and Boness, 1996). However, for Mohor gazelle, we have observed no significant differences between sexes of calves at birth [males: mean \pm standard error $=6.19 \pm 0.186 \mathrm{~kg}(\mathrm{~N}=17)$; females: mean \pm standard error $=5.91 \pm 0.204 \mathrm{~kg}(\mathrm{~N}=13) ; \mathrm{F}_{1,28}=1.018 ; \mathrm{p}=0.322$; for similar results see Alados and Escós, 1994; Byers and Moodie, 1990]. It therefore seems that there is no differential maternal investment between sexes during gestation in the Mohor gazelle.

Lactation has been proposed as the most costly phase of the reproductive cycle (Bercovitch et al., 2004). Its cost can be estimated by examining suckling frequency, maternal weight loss, milk intake, infant growth or infant mortality. Unfortunately, the 
only such data we have available is perinatal mortality (Ibañez et al., submitted), and they show that there is no statistical difference in mortality between sexes during the first 30 days of life. It seems that for the Mohor gazelle, there is no differential cost to the mother in rearing male or a female offspring.

The possibility that suckling frequency, milk intake and infant growth may be different between sexes can be ruled out, as we would then also expect differences in calf body weight at 30 days, and according to Cano (1991) this is not the case in Mohor gazelle. Unfortunately, we have no information on mother weight loss during suckling. As long as this information is unavailable, we cannot rule out the possibility of a differential maternal investment in Mohor gazelles, although to date, it is not supported by the data.

Alternatively, the above mentioned differences found between Cuvier's and Mohor gazelles might be due to differences in the actual homozygosis level. Inbreeding estimation is based on pedigrees. Pedigrees provide information about the relatedness among individuals within the population, but the actual genetic homozygosis level very much depends on the original genetic variability in the founders. By using microsatellites to estimate heterozygosity, Ruíz López et al. (2009) have shown that the relationship between inbreeding and molecular metrics in G. cuvieri housed at "La Hoya" is very similar to that expected for outbred and unrelated founders. In contrast, no relationship was found for Mohor gazelle which suggest lower level of genetic variability in the founders of the latter species.

Contrary to expectations, maternal age was not related to offspring sex in surviving calves at 30 days of life in any of the gazelle species studied. Saltz (2001) suggests that maternal age is the most common determinant of progeny sex ratio, although Hewison et al. (2002) argues against it, stating that maternal age may be a correlate of progeny sex ratio in some cases, but only as a proxy for other maternal characteristics such as body condition. He also argues that a correlation between maternal age and progeny sex ratio may be hypothesised following the Trivers and Willard (1973) model if age is somehow related to maternal body condition, but this does not constitute a direct determining influence of age on progeny sex ratio. Our results agree rather with this idea as they do not support the value of maternal age for adaptive sex allocation in the two gazelle species studied (see Kohlmann, 1999; Kruuk et al., 1999; Novellie et al., 1996; for other ungulate species). 
Against expectations we have not found significant relationships between offspring sex and maternal experience in these gazelle species. It could be argued that captive breeding management might be the cause of this disagreement between what is expected and found. In the past, at the Experimental Field Station "La Hoya", females have not always been included in a breeding herd as soon as they reach sexual maturity, but older (as old as 4-5 years of age). So very likely, the effect of primiparity on progeny sex ratio in our captive population of Cuvier's gazelle is obscured by management, as some females first bred when they had already reached their full growth (Saltz and Rubenstein, 1995).

In Cuvier's gazelle litter size has no effect on offspring sex once the effect of the sex of the littermates is taken into account. Although some works (Frank, 1990; Gosling, 1986; Williams, 1979) states that the Trivers-Willard (1973) predictions cannot be applied to litter size greater than one, mainly because when both the sex ratio and the number of calves should be adjusted simultaneously, good quality mothers may gain more by increasing the number of offspring than by adjusting the sex ratio of the broods, our results do not support such statements but rather fit the predictions derived from Trivers-Willard model: mother in good conditions (less inbred) produce the sex with higher fitness returns (i.e., male), no matter if born at single or twins brood. Cassinello and Gomendio (1996) found a similar result in the Saharan arrui, (Ammotragus lervia sahariensis), with higher ranked mother (assumed to be in better body conditions) producing singleton male and lower ranked mother producing twins females. From our result follows that, in this species, females are cheaper to produce than males, even if born as co-twins and this is of relevance when taking managing decisions.

\section{Implication to ex situ conservation programs}

Ex situ conservation programs can represent important tools to help assure the survival of many threatened species. Captive breeding provides the tool to rear sustained populations. Knowledge about biology of such species is critical for managing breeding programmes but also for predicting the likely viability of eventual reintroductions. Result of our species-based may help captive breeding of the species involved.

Inbreeding avoidance is a common practice in captive breeding programs due to its negative fitness consequences (e.g., Boakes et al., 2007; Fredrickson and Hedrick, 
2002; Joron and Brakefield, 2003; Cassinello, 2005). However, our results for Cuvier's gazelles have shown that the higher the inbreeding coefficient of the mother the higher the probability of producing daughters which is advantageous in captive polygynous species as a way of solving the organizational problems posed to captive breeders of where and how to keep the surplus males. Although it has been demonstrated that too much outbreeding can have negative consequences (Bateson, 1978, 1982) and that mating with a relative is more common than generally assumed in nature (Jordal et al., 2002, Riechert and Roeloffs, 1993), the conservative approach we propose for the management programs of Cuviers' gazelle is to avoid inbreeding. However, the possibility of kin-mating should not be ruled out for ever. Considering that breeding from highly inbred individuals is not necessarily bad because they might still be genetically important at population level, in practice, the manager of this captive population might be able to combine inbred females with unrelated or slightly unrelated partners, resulting in a non- or slightly inbred offspring (very likely a daughter if our results are considered), which help to solve the short term practical problem of surplus males within the EEP of the species. This practice suggested for captive Cuvier's gazelle agrees with that outlined by other authors: in captive breeding populations where offspring sex ratio is dependent on female condition, manipulation of offspring sex ratios should be considered as a management option as it may increase the number of females that can be released (Lenz et al., 2007, Robertson et al., 2006, Tella, 2001).

Many variables are likely to affect progeny sex ratio, and we have analysed only a few. Most of them are not clearly a black and white matter. In captive populations, even the time the captive breeding program has been in operation may have an effect on the results (compare results by Alados and Escós, 1991, 1994; Cano, 1991; Cassinello, 2005). We strongly suggest that data in such captive breeding programs be reviewed from time to time, as some variables may affect sex allocation differently depending on their value at a particular time. Future research should focus on this issue.

\section{Acknowledgements}

This work has been partially supported by project CGL 2008-00562/BOS of the Spanish Ministry of Science and Innovation, and by the European Regional Development Fund. B. I. was supported by a CSIC predoc grant. The authors thank G. Espeso, current EEP coordinator for the Mohor gazelle, who kindly provides us with 
useful historical information of captive populations of this species, and helps us to use the SPARK software; D. Parejo for assistance with the statistical analysis; the staff of the Finca Experimental La Hoya for expert handling of the animals of the breeding programmes; and Deborah Fuldauer for correcting the language. Two anonymous referees greatly improved the manuscript with their suggestions.

\section{References}

Alados, CL, Escós, JM (1991). Phenotypic and genetic characteristics affecting Lifetime reproductive success in female Cuvier's. dama and dorcas gazelles (Gazella cuvieri, G. dama and G. dorcas). Journal of Zoo Zool Lond 223:307-321

Alados CL, Escós JM (1994) Variation in the sex ratio of low dimorphic polygynous species with high levels of maternal reproductive effort: Cuvier's gazelle. Ethology Ecology \& Evolution 6: 301-311

Aulagnier S, Thévenot M (1986) Les ongulés suavages du Maroc. Constat d'une regresión alarmante. Le courrier de la Nature 104:16-37

Barbosa A, Espeso G (2005) International studbook. Gazella dama mhorr. CSIC. Madrid. 128 pp. (ISBN: 84-00-08380-6)

Bateson, PPG (1978) Sexual imprinting and optimal outbreeding. Nature 273: 259-260.

Bateson, PPG (1982) Preferences for cousins in Japanese quail. Nature 295: 236-237.

Bennett ET (1833) Characters of a new species of Antilope (Antilope Mhorr). Proceedings of the Zoological Society of London 1833:1-3

Bercovitch FB, Bashaw MJ, Penny CG, Pieches RG (2004) Maternal investment in captive giraffes. J Mammal 85:428-431

Beudels, R.C., Devillers, P., Lafontaine, R.-M., Devillers-Terschuren, J. \& Beudels, M.O. 2005. Sahelo-Saharan Antelopes. Status and Perspectives. CMS Technical Series Publication, No 11. UNEP/CMS Secretariat, Bonn. Germany.

Blaxter KL, Hamilton WJ (1980) Reproduction in farmed red deer. Calf growth and mortality. J agric Sci Camb 95:275-284

Boakes EH, Wang J, Amos W (2007) An investigation of inbreeding depression and purging in captive pedigreed populations. Heredity 98:172-182

Byers JA, Moodie JD (1990) Sex-specific maternal investment in pronghorn, and the question of a limit on differential provisioning in ungulates. Behav Ecol Sociobiol $26: 157-164$

Cano MM (1991). El antílope Mohor, Gazella (Nanger) dama mhorr Bennett 1833 en cautividad. Granada: Universidad de Granada. Servicio de Publicaciones, D.L. 84-3381334-X 
Carranza J (2004) Sex allocation within broods: the intrabrood sharing-out hypothesis Behav Ecol 15:223-232

Cassinello J (1997) High levels of inbreeding in captive Ammotragus lervia (Bovidae, Artiodactyla): Effects on phenotypic variables. Canadian Journal of Zoology 75:17071713

Cassinello J (2005) Inbreeding depression on reproductive performance and survival in captive gazelles of great conservation value. Biological Conservation 122:453-464

Cassinello J, Gomendio M (1996) Adaptive variation in litter size and sex ratio at birth in a sexually dimorphic ungulate. Proc. R. Soc. Lond. 263:1461-1466

Cassinello J, Gomendio M, Roldan ERS (2001) Relationship between coefficient of inbreeding and parasite burden in endangered gazelles. Conservation Biology 15:11711174

Charlesworth D, Charleswrth B (1987) Inbreeding depression and its evolutionary consequences. Ann Rev Ecol and Syst, 18:237-268

Charpentier M, Setchell JM, Prugnolle F, Wickings SEJ, Piegnot P, Balloux F, Hossaert-Mckey M (2006) Life history correlates of inbreeding depression in mandrills (Mandrillus sphinx). Molecular Ecology 15:21-28

Clutton-Brock TH, Guinness FE, Albon SD (1982) Red deer. Behavior and ecology of two sexes. Univ Chicago Press, Chicago

Clutton-Brock TH, Iason GR (1986) Sex ratio variation in mammals. Q. Rev Biol 61:339-374

Coltman DW, Don Bowen W, Wright JM (1998) Birth weight and neonatal survival of harbour seal pups are positively correlated with genetic variation measured by microsatellites. Proc R Soc Lon B 265:803-809

Côté SD, Festa-Bianchet M (2001) Offspring sex ratio in relation to maternal age and social rank in mountain goats (Oreamnos americanus). Behav Ecol Sociobiol 49:260265

Engqvist, L (2005) The mistreatment of covariate interaction terms in linear model analyses of behavioural and evolutionary ecology studies. Anim Behav 70:967- 971

Espeso, G, Barbosa, A (2010) International Studbook for Mohor gazelle, Gazella dama mhorr. Download version in http://www.eeza.csic.es/eeza/documentos/STBDA.txt.

Faust LJ, Thompson SD (2000) Birth sex ratio in captive mammals: patterns, biases, and the implications for management and conservation. Zoo Biology 19:11-25

Festa-Bianchet M, Jorgenson JT, Lucherini M, Wishart WD (1995) Life history consequences of variation in age of primiparity in bighorn ewes. Ecology 76:871-881

Fisher, RA (1930) The Genetic Theory of Natural Selection, Clarendon Press, Oxford 
Frank AS (1990) Sex allocation theory for birds and mammals. Ann Rev Ecol Syst 21:13-55

Fredrickson R, Hedrick P (2002) Body size in endangered Mexican wolves: effects of inbreeding and cross-lineage matings. Animal Conservation 5:39-43

Gomendio M, Cassinello J, Roldan ERS (2000) A comparative study of ejaculate traits in three endangered ungulates with different levels of inbreeding: fluctuating asymmetry as an indicator of reproductive and genetic stress. Proc R Soc Lond B 267:875-882

Gosling LM, 1986. Biased sex ratios in stressed animals. Am Nat 127: 93-896.

Hewison MAJ, Andersen R, Gaillard JM, Linnel JDC, Delorme D (1999) Contradictory findings in studies of sex ratio variation in roe deer (Capreolus capreolus). Behav Ecol Sociobiol 45:339-348

Hewison MAJ, Gaillard J-M, Blanchard P Festa- Bianchet, M (2002) Maternal age is not a predominant determinant of progeny sex ratio variation in ungulates. Oikos 98:334-339

Ibañez, MB, Moreno, E, Barbosa, A. (submitted) Factors affecting perinatal mortality in two endangered gazelles; a case study in captive populations.

ISIS (2004) International Species Information System: SPARK Single Population Animal Record Keepng System Software, version 1.54, Eagan, MN, USA.

Jordal, BHR, Beaver, RA, Normark, BB, Farrell, BD (2002) Extraordinary sex ratios and the evolution of mate neoteny in sib-mating Ozopemon beetles. Biol. J. Linn. Soc 75: 353-360.

Joron M, Brakefield PM (2003) Captivity masks inbreeding effects on male mating success in butterflies. Nature 424:191-194

Kingdon J (1997) The Kingdon Field Guide to African Mammals. Academic Press, London and New York: Natural World

Kirkwood JK, Gaskin CD, Markham J (1987) Perinatal mortality and season of birth in captive wild ungulates. Veterinary Record 120:386-390

Knut HR, Holand Ø, Mysterud A, Tverdal A, Kumpula J, Nieminen M (2007) Male phenotypic quality influences offspring sex ratio in a polygynous ungulate. Proc. R. Soc. B 274:727-733

Kohlmann SG (1999) Adaptive fetal sex allocation in elk: evidence and implications. J Wildl Manage 63:1109-1117

Kruuk LEB, Cluton-Brock TH, Albon SD, Pemberton JM, Guinness FE (1999) Population density affects sex ratio in red deer. Nature 399:459-461

Kühl A, Mysterud A, Erdnenov GI, Lushchekina AA, Grachev IA, Bekenov AB, Milner-Gulland EJ (2007) The "big spender" of the steppe: sex-specific maternal allocation and twinning in the saiga antílope. Proc R Soc B 274:1293-1299 
Landete-Castillejos T, García A, López-Serrano FR, Gallego L (2005) Maternal quality and differences in milk production and composition for male and female Iberian red deer calves (Cervus elaphus hispanicus). Behav Ecol Sociobiol 57:267-274

Landete-Castillejos T, Gortázar C, Vicente J, Fierro Y, García A, Gallego L (2004) Age-related foetal sex ratio bias in Iberian red deer (Cervus elaphus hispanicus): are male calves too expensive for growing mothers? Behav Ecol Sociobiol 56:1-8

Lenz, TL, Jacob, A, Wedekind, C (2007) Manipulating sex ratio to increase population growth: the example of the Lesser Kestrel. Animal Conservation 10:236-244

Loggers CO, Thévenov M, Aulagnier S (1992) Status and distribution of Moroccan wild ungulates. Biological Conservation 59:9-18

Magin CD, Johnson TH, Groombridge B Jenkins M, Smith H (1994) Species extintions, endangerment and captive breeding. In: Onley PJS, Mace GM, Feistner ATC (eds) Creative Conservation: Interactive management of wild and captive animals, Chpman and Hall, London, pp 3-30

Moreno E, Espeso G (2008) International studbook. Cuvier's gazelle (Gazella cuvieri). CSIC. Roquetas de Mar, Almería. 152 pp. (ISBN:978-84-936827-0-5)

Novellie PA, Millar PS, Lloyd PH (1996) The use of Vortex simulation models in a long term program of re-introduction of an endangered large mammal, the Cape mountain zebra (Equus zebra zebra). Acta Oecol 17:657-671

Ogilby WM (1841) Proceedings of the Zoological Society (1836-40), pp. 34-35

Ono KA, Boness DJ (1996) Sexual dimorphism in sea lion pups: differential maternal investment, or sex-specific differences in energy allocation? Behav Ecol Sociobiol $38: 31-41$

Ralls K, Brugger K, Ballou J (1979) Inbreeding and juvenile mortality in small populations of ungulates. Science 206:1101-1103

Riechert, SE, Roeloffs, RM (1993) Evidence for and consequences of inbreeding in the cooperative spiders. Pp 283-303 in N. Wilmsen Thornhill, ed. The natural history of inbreeding and outbreeding. University of Chicago Press, Chicago, IL.

Roldan ERS, Gomendio M, Garde JJ, Espeso G, Ledda S, Berlinguer F, A del Olmo, Soler AJ, Arregui L, Crespo C, Gonzalez R (2006) Inbreeding and reproduction in endangered ungulates: preservation of genetic variation through the organization of genetic resource banks. Reprod Dom Anim 41:82-92

Ruiz-López, MJ; Roldan, ERS; Espeso, G, Gomendio, M (2009) Pedigrees and microsatellites among endangered ungulates: what do they tell us? Molecular Ecology 18: $1352-1364$

Robertson, BC, Elliott, GP, Eason, DK, Clout, MN, Gemmell, NJ (2006) Sex allocation theory aids species conservation. Biology Letters 2:229-231 
Russello, MA, Amato, G (2004) Ex-situ population management in the absence of pedigree information. Molecular Ecology 13: 2829-2840.

Saltz D (2001) Progeny sex ratio variation in ungulates: maternal age meets environmental perturbation of demography. Oikos 94:377-383

Saltz D, Rubenstein DI (1995) Population dynamics of a reintroduced Asiatic wild ass (Equus hemionus) herd. Ecological applications 5:327-335

Tella JL (2001) Sex-ratio theory in conservation biology. TREE 16:76-77

Trivers RL, Willard DE (1973) Natural selection of parental ability to vary the sex ratio of offspring. Science 179:90-92

Valverde, JA (2004) Memorias de un Biólogo Heterodoxo, Vol III: Sahara, Guinea, Marruecos: Expediciones Africanas. Editorial V \& V. Madrid.

Walther FR (1990) Gazelles and related species. In: Parker SP (ed) Grzimek's Encyclopaedia of Mammals, McGraw-Hill, New York, Volume 5, pp. 462-484

Williams GC (1979) The question of adaptive sex ratio in outcrossed vertebrates. Proc R Soc Lond 205:567-580

Wolff JO (1988) Maternal investment and sex ratio adjustment in American bison calves. Behav Ecol Sociobiol 23:127-133

Wright LI, Tregenza T, Hosken DJ (2008) Inbreeding, inbreeding depression and extinction. Conserv Genet 9:833-843. 
Table 1: Descriptors (continuous variables) for the total populations of 555 individual offspring of Cuvier's gazelles and 678 of Mohor gazelles included in this study. Range (minimum and maximum), mean and standard deviation are shown.

$\begin{array}{lccccr} & \text { Mean } & \text { Minimum } & \text { Maximum } & \text { Std Dev } & \text { N } \\ \text { Cuvier's gazelle } & & & & & \\ \quad \text { Maternal inbreeding coefficient } & 0.156 & 0.000 & 0.375 & 0.072 & 555 \\ \quad \text { Maternal age (days) } & 1611.87 & 345.00 & 4785.00 & 934.36 & 555 \\ \begin{array}{l}\text { Mohor gazelle } \\ \quad \text { Maternal inbreeding coefficient }\end{array} & 0.200 & 0.000 & 0.429 & 0.088 & 678 \\ \quad \text { Maternal age (days) } & 1977.23 & 319.00 & 5736.00 & 1145.86 & 678\end{array}$


Table 2: Effects of the maternal variables on the offspring sex of Cuvier's gazelle and Mohor gazelle. For Cuvier's gazelle the effect of litter size considering the sex of the littermates (litter size x littermate sex factor) is also shown (bottom raw).

\begin{tabular}{lcccccc} 
& \multicolumn{2}{c}{ Cuvier's gazelle } & & \multicolumn{2}{c}{ Mohor gazelle } \\
\cline { 2 - 3 } \cline { 6 - 7 } Maternal Variable & Test statistic & $P$ & & Test statistic & $P$ \\
\hline Inbreeding coefficient & $\mathrm{F}_{1,203}=4.74$ & 0.030 & & $\mathrm{~F}_{1,107}=0.12$ & 0.733 \\
Age (raw) & $\mathrm{F}_{1,203}=2.86$ & 0.093 & & $\mathrm{~F}_{1,107}=3.35$ & 0.700 \\
Age (squared) & $\mathrm{F}_{1,203}=3.03$ & 0.083 & & $\mathrm{~F}_{1,107}=3.22$ & 0.076 \\
Experience & $\mathrm{F}_{1,203}=1.61$ & 0.205 & & $\mathrm{~F}_{1,107}=0.49$ & 0.485 \\
Identity (Studbook number) & $\mathrm{Z}=0.99$ & 0.162 & & $\mathrm{Z}=0.69$ & 0.247 \\
Litter size x littermate sex & $\mathrm{F}_{1,203}=1.93$ & 0.150 & & - & -
\end{tabular}


Figure 1: Graph showing male vs female offspring produced according to maternal inbreeding coefficient by Cuvier's gazelle. The regression line is from a logistic regression model including offspring sex as independent variable and maternal inbreeding coefficient as dependent variable.

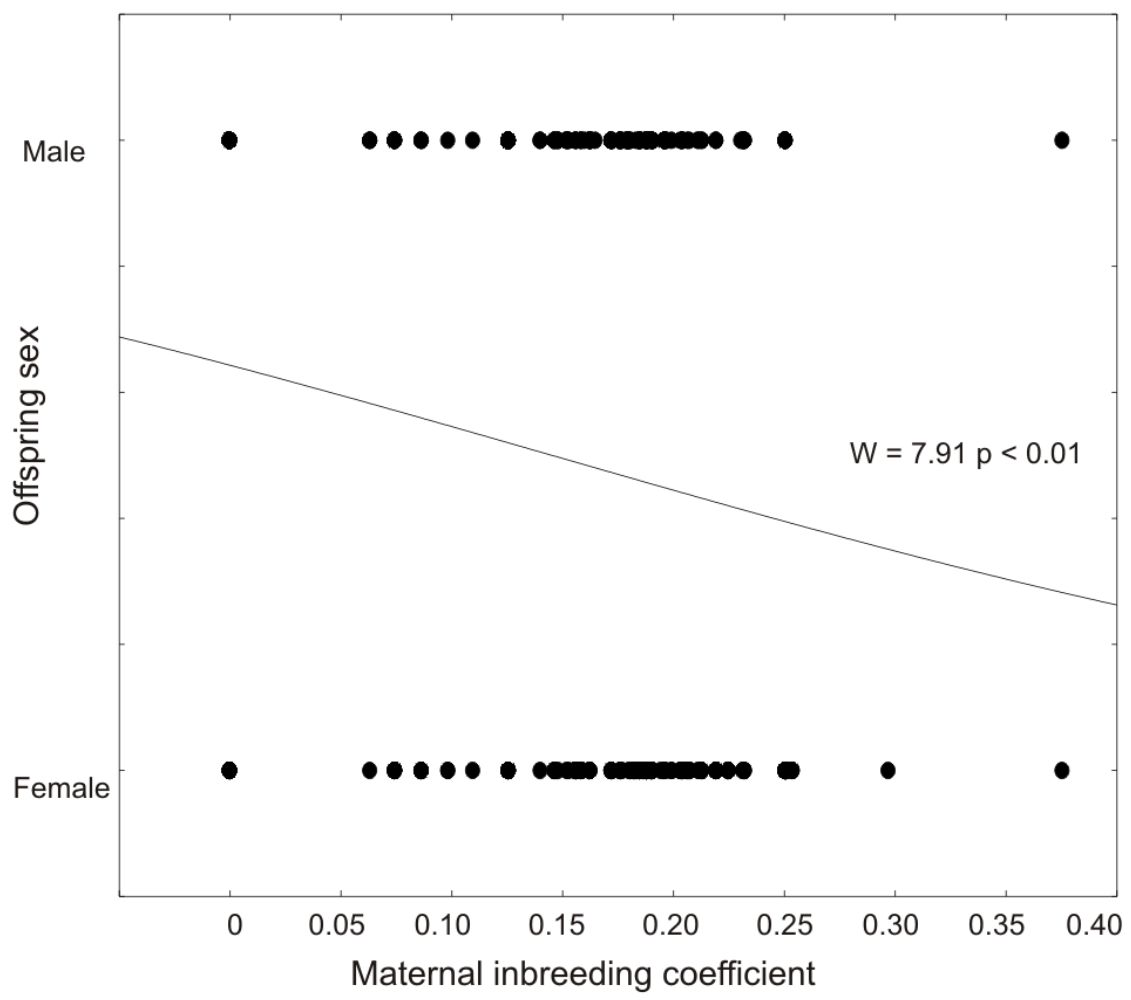

